\title{
Por que estudar Bachelard?
}

Marly Bulcão ${ }^{1}$

Para mim, é sempre um prazer muito grande falar de Gaston Bachelard e divulgar o pensamento deste filósofo que, acredito, tem uma importância incontestável. Para responder à pergunta do Gabriel, "Por que estudar Bachelard?", vou começar dizendo que considero a filosofia como um exercício de pensar permanente e sempre recomeçado. Mas, para isso, é necessário que haja alguma provocação. Ao ler Bachelard concluímos que estamos diante de um pensamento provocador, pois nos impulsiona a construir novas ideias. Não se pode ler Bachelard e permanecer passivo, não se pode ler Bachelard e não ter alguma reação, ele emociona, ele suscita admiração, ele causa, até mesmo, reações contrárias ao seu pensamento. Justamente porque sua obra é provocante e sua filosofia tem uma fecundidade heurística irresistível.

Lendo Bachelard criamos novas ideias. Sua filosofia é instigante, é desconcertante, eu diria que é, até mesmo, uma filosofia ousada. Ousada porque remete o leitor a uma atitude transgressora. Bachelard nos propõe transgredir pressupostos da tradição francesa, da tradição filosófica europeia, sempre no sentido de chegar a ideias inovadoras.

Lendo Bachelard somos conduzidos a um reino filosófico inteiramente novo. Bem diferente dos filósofos seus contemporâneos, que por serem acadêmicos, eram também formalistas, Bachelard violenta hábitos que tínhamos e que considerávamos sólidos, afasta certezas adquiridas e nos impulsiona em direção à novidade e à construção de um futuro intelectual mais iluminado.

Em seu livro Le jour et la nuit, ( $O$ dia e a noite) Dominique Lecourt afirma: "o bachelardismo vem de uma longa noite" (LECOURT, 1974, p.15) esclarecendo que houve, de início, uma reação por parte da academia contra as ideias bachelardianas que só começaram a ser aceitas, por alguns intelectuais, após 10 anos de suas primeiras publicações. Bachelard era, principalmente, um forte opositor das filosofias dogmáticas. A rejeição às primeiras publicações bachelardianas deve-se ao fato de que predominavam na Sorbonne, o idealismo, ao qual se

\footnotetext{
1. Universidade do Estado do Rio de Janeiro, Rio de Janeiro, e-mail: marlybu@uol.com.br
} 
filiavam autores diversos, o positivismo comteano e a filosofia de Émile Meyerson, cujas ideias eram bem diferentes daquelas defendidas por Bachelard.

Bachelard é um pensador original. Tendo nascido em 1884 em Bar-sur-Aube, cidade provinciana da região da Champagne, viveu sua infância em contato com a natureza, transferindo-se, na maturidade para Paris cosmopolita e industrial, onde viveu até sua morte em 1962 na Paris cosmopolita e industrial. Ao ingressar na Sorbonne em 1940, como professor titular da cadeira de Filosofia e História das Ciências, trouxe consigo a marca daqueles primeiros anos, quando brincava, ainda criança, tendo ao seu redor os quatro elementos, a água dos riachos, o ar puro que respirava dos bosques ancestrais de sua cidade, "nos quais, eu sei, meu pai se perdeu um dia" (BACHELARD, 1998, p.172), o fogo das fogueiras de suas lembranças que acendia com "os companheiros para fundar o foyer da escola dos gazeteiros" (BACHELARD, 2002, p.29), sem que os pais zelosos soubessem o que faziam. Daí a construção de uma filosofia e de um pensamento "rural", segundo Georges Canguilhem, o que provocava a oposição dos acadêmicos.

Voltando à questão "Por que estudar Bachelard", devo dizer que é importante aprofundar a noção bachelardiana de razão, totalmente inovadora. Bachelard defende um racionalismo que contraria pressupostos da tradição francesa predominantemente cartesiana. Contemporâneo das revoluções científicas, com o surgimento da teoria da relatividade, da mecânica quântica e das geometrias não euclidianas, Bachelard aponta a mudança de paradigmas científicos que rompem, segundo ele, com os princípios da ciência clássica. Mostra, então, que a ciência progride de forma descontínua, renegando conhecimentos anteriores. Trata-se de uma perspectiva inteiramente inovadora e original, pois, para Descartes, as teorias científicas deviam estabelecer princípios e axiomas evidentes, definitivos e fundamentais a fim de deduzir destes os demais conhecimentos. Conforme mostra Bachelard, apesar da descontinuidade e da negação do saber, a razão caminha, traçando uma linha de progresso, pois as novas teorias são sempre mais abrangentes que as anteriores, no sentido de que explicitam um maior número de fenômenos e acabam, neste processo dialético e progressivo, por incluir a teoria anterior, como uma parte restrita do novo sistema.

Outro motivo porque é importante estudar Bachelard é pelo fato dele propor também nova concepção de imaginação, pois conforme diz muito bem José Américo Pessanha, ao lado do Bachelard, diurno existe também um Bachelard noturno que vai inovar a noção de imaginação 
que, até então, era abordada, pela tradição, tanto racionalista quanto empirista, a partir da teoria do conhecimento, ou seja, relacionando a imagem com a percepção ou com a ideia, o que resultava em que esta fosse sempre considerada inferior a ambas. Voltando-se para os textos literários ou para obras de arte, Bachelard vai substituir o enfoque psico-gnoseológico pelo enfoque estético, atribuindo autonomia à imaginação que passa a ser considerada como acontecimento objetivo que integra uma imagética. Mergulha, assim, no abismo da imaginação descompromissada e livre.

É importante estudar Bachelard, portanto, porque ele nos ensina a apreender a imaginação que permeia textos literários como os de Edgar Alan Poe e Novalis, a imaginação que está presente na arte da pintura como as de Monet e da escultura como as do Eduardo Chillida, escultor espanhol, autor de obras lindíssimas como o Pente dos Ventos que fica na costa da Espanha, numa rocha que invade o mar, enquanto as ondas a atravessam, causando enorme emoção aos visitantes.

A imaginação, para Bachelard tem, pois, uma autonomia e um dinamismo próprio, não tem causa, deve ser apreendida na sua imediatez, pela repercussão e ressonância que provoca no sujeito. É preciso ressaltar, entretanto, que a imagem não é vivenciada somente pelo artista no ato de criação, o observador da arte também é capaz, não só de apreendê-la como também é capaz de vivenciar, a partir dela, uma proliferação de novas imagens. O paradoxo difícil de compreender é como uma imagem que é única e singular pode ser apreendida por uma alma estranha a do artista. Conforme afirma Bachelard em A poética do espaço, não é necessário conhecer o passado do poeta para darmos nossa adesão à obra por ele criada. Mostra que há, entre o artista e o leitor da obra de arte, uma comunicação transubjetiva que permite partilhar o processo imagético, sem com isso comprometer os aspectos singulares e únicos das imagens vivenciadas por cada um.

A imagem não tem causa, não tem origem, não é determinada; a imagem é apreendida fenomenologicamente e não pode ser compreendida recorrendo à interpretação. Daí a crítica bachelardiana aos psicanalistas, cuja preocupação terapêutica faz com que estes se afastem da imagem e se voltem para a vida e o passado do poeta. Em A poética do espaço, Bachelard, opondo-se ao método da psicanálise, afirma categoricamente que "o psicanalista deixa o estudo ontológico da imagem; ele aprofunda a história de um homem; ele vê, mostra os sofrimentos secretos do poeta, ele explica a flor pelo estrume" (BACHELARD, 1998, p.12). 
Neste sentido, a imagem não tem origem, nada a explica, não é nem reprodução, nem o substituto de um objeto percebido, nem uma sombra da ideia, a imagem é resultado de uma imaginação eminentemente criadora, de uma imaginação que inventa um mundo novo.

Bachelard exalta, na vertente poética, o devaneio que nos leva a habitar a nossa intimidade, o nosso eu mais profundo, a nossa primitividade. Através do devaneio, deixamos de ter um nome, deixamos de ter uma história, nos tornando filhos do cosmos. Através do devaneio, ao criar novas imagens, atingimos a superação do próprio eu, o que faz com que o eu se renove constantemente ao longo de sua trajetória imagética.

É importante estudar Bachelard para se compreender a polaridade e a oposição das duas vertentes que se alternam numa coreografia dinâmica e contrastante, deixando entrever a ambiguidade que habita o ser humano. A metáfora da casa onírica apresentada em $A$ poética do espaço expressa bem esta polaridade, através do conceito de verticalidade.

Conforme mostra Bachelard, a casa onírica é imaginada como um ser vertical. A verticalidade da casa é assegurada pela polaridade do porão e do sótão, uma polaridade tão profunda que é, em última instância, a expressão mesma da ambiguidade humana. No porão, as sombras dançam, é onde nossos medos de infância se tornam mais intensos e somos envoltos pela escuridão, visitando labirintos ocultos que nos conduzem ao desconhecido. Quando abandonamos o porão e subimos ao sótão, deixamos para trás nossos sonhos e devaneios, alcançamos a luminosidade, penetramos na altitude clara dos projetos racionalizados. Conforme mostra Bachelard, é possível opor a racionalidade do telhado à irracionalidade do porão. Somente assim, compreendemos a dualidade da razão e da imaginação, expressa pela polaridade do porão e do sótão. Somos, pois, eternos viajantes do porão ao sótão. Cada ser humano vivencia esta polaridade ao longo de sua vida, passando do poético ao conceitual, da ciência à poesia, da razão à imaginação e vice-versa.

Em A poética do espaço, Bachelard ilustra muito bem isso, mostrando como ele, um filósofo rural que viveu sua infância no campo, onde habitava numa casa com porão e sótão, sentiu-se ilhado na Paris cosmopolita, onde passou o período final de sua vida. Afirma:

Em Paris não há casas. Em caixas superpostas vivem os habitantes da grande cidade [...] Coisa inimaginável, para quem sonha com casas, os arranha-céus não tem porão. Da calçada até o teto, os cômodos se acumulam e a tenda de um 
céu sem horizontes encerra a cidade inteira. Os edifícios só têm na cidade, uma altura exterior. Os elevadores destroem os heroísmos da escada. Já quase não há mérito em morar perto do céu. E o em nossa casa não é mais que uma simples horizontalidade (BACHELARD, 1998, p.42).

Mais um motivo pelo qual considero importante o estudo de Bachelard, deve-se ao convite inédito que ele nos faz quando nos pede para pensarmos à contratempo. Propõe, então, a recusa do tempo horizontal e contínuo, do tempo da vida cotidiana, do tempo da história e defende que o verdadeiro tempo é o instante, o aqui e o agora, o instante que existe entre dois nadas. Da mesma forma, a imagem surge no instante para logo em seguida morrer, o que não impede que nós a possamos sentir em profundidade.

Na vertente epistemológica, a verdade da razão científica é a atualidade, não há saber verdadeiro que se prolongue continuamente na linha da eternidade, pois o progresso se dá por rupturas, é sempre descontínuo. Para Bachelard, a história do nosso eu ou a história das ciências é uma construção da inteligência que consegue elaborar uma superposição de instantes. Podemos, assim, dizer que é possível existirem diversas histórias, inclusive do nosso próprio eu.

Como já dissemos, Bachelard é um crítico voraz da psicanálise, devendo ser ressaltado que se trata da psicanálise que chegava na França naquele momento e que ele conheceu por intermédio dos psicanalistas seguidores de Freud, como Maria Bonaparte e outros. Afirma em $A$ poética do espaço que o psicanalista compreende bem a natureza do poeta, mas não consegue apreender a imagem em sua especificidade, pois esta é original e imprevisível. No entanto, aquele que é apreciador da arte não precisa conhecer os sofrimentos do poeta para se emocionar com as imagens poéticas.

Proponho que estudemos Bachelard, porque sua obra, mesmo sendo por demais complexa e abrangente, tem muitos aspectos relevantes que nos levam a conhecê-la com admiração profunda. Escolhemos, nesta entrevista, apenas, alguns destes aspectos, já que nosso tempo é limitado. É preciso dizer também que a importância de se ler o filósofo, advém do fato de que as categorias bachelardianas podem ser aplicadas em campos diversos do saber. Consciente disto, resolvi aplicá-las a campos do saber que não tinham sido objeto de sua reflexão como, por exemplo, o cinema. Devo dizer que foi uma decisão um tanto ousada, pois num encontro que tive com sua filha, Suzanne Bachelard, esta me disse que seu pai nunca entrara 
numa sala de projeção. Fiquei um tanto duvidosa, pois, morando em Paris e lecionando na Sorbonne, era provável que este tivesse visto algum filme ou documentário. Suzanne, já bem idosa, na época de nosso encontro, talvez não estivesse muito lúcida em relação às lembranças. Mas, é verdade que na obra bachelardiana não existe, de fato, nenhuma referência ao cinema.

Foram cursos maravilhosos na Universidade do Estado do Rio de Janeiro - UERJ, através dos quais consegui trazer Bachelard para o cinema. Devo ressaltar que os alunos contribuíram muito para o sucesso das aulas, pois estes eram excelentes e muito interessados. Costumávamos passar um filme e cada um fazia sua análise, trazendo, para isso, as categorias bachelardianas. Em seguida havia um debate que era sempre caloroso. Os cursos tiveram como resultado a publicação pela Editora Ideias e Letras de um livro, por mim organizado intitulado Luz, Câmera, Filosofia: Mergulho na Imagética do Cinema. Foi um período muito bom da minha vida que ainda hoje me lembro com saudades.

Em 2014, participei juntamente com a Profa Constança Marcondes Cesar do Congresso da Association de Philosophie de Langue Française, realizado em Marrocos, cujo tema era Le possible et l'impossible. Dando prosseguimento aos estudos de Bachelard e o cinema, apresentei um trabalho que tinha como intuito mostrar que o cinema consegue concretizar o impossível. Mostrei uma edição pequena de quinze minutos do filme $O$ cão Andaluz de Buñel, apresentando depois uma reflexão sobre o filme através da relação de Bachelard com o surrealismo, tendo havido em seguida um debate bem interessante.

Com o intuito de reforçar o que dissemos sobre a abrangência da obra bachelardiana vamos relembrar aqui também o colóquio, realizado em julho de 2012 no Castelo de Cerisy na Normandia. Era a comemoração de cinquenta anos da morte de Bachelard e decidiram realizar em Cerisy justamente porque neste castelo tinha acontecido anos atrás o primeiro colóquio sobre Bachelard com a presença do próprio filósofo, o que fez do Castelo de Cerisy um marco importante para os pesquisadores bachelardianos.

O colóquio de 2012 foi organizado por Jean-Jacques Wunenburger, especialista francês, de renome internacional que escolheu um tema interessante: Gaston Bachelard: science et poétique, une nouvelle éthique? Quarenta pesquisadores de países diversos foram convidados a participar do evento, entre os quais me encontrava, assim como a Profa Constança Marcondes Cesar. Embora não haja nas obras bachelardianas, de forma explícita, uma análise sobre ética, 
todos os pesquisadores puderam elaborar, devido a abrangência da obra do filósofo, uma reflexão indireta sobre o tema da ética.

Apresentei, neste colóquio, um trabalho que se intitulava Gaston Bachelard e o Complexo de Prometeu: por uma ética da desobediência, trabalho este que provocou ao seu término um debate, do qual participaram muitos pesquisadores. Procurei mostrar no trabalho que o herói grego que roubou o fogo dos deuses simboliza a desobediência, atitude esta que deve reger a ética do humano. Cabe ao homem, ao trilhar os caminhos da razão e da imaginação, lançar-se na região da imprudência a fim de renegar a tradição e se voltar para a busca de novos valores e de novos fundamentos. Em Fragmentos de uma poética do fogo, Bachelard afirma:

O herói Prometeu é o símbolo da desobediência construtora. É preciso desobedecer aos pais para fazer melhor do que os pais. Desobedecer para agir é a divisa do criador. A história dos homens em seus progressos é uma linha de atos prometeicos. Mas, no tecido mesmo de uma vida individual, a autonomia conquistada é feita de pequenas desobediências prometeicas, de desobediências inteligentes, bem associadas, pacientemente perseguidas (BACHELARD, 1988, p.125-126).

Ressaltando mais um aspecto de importância capital para que se estude Bachelard queremos destacar as ideias pedagógicas que permeiam seus escritos. Considerando que hoje estamos vivendo no Brasil um momento em que a educação é menosprezada por parte do governo federal, lendo Bachelard podemos encontrar uma pedagogia da razão e uma pedagogia da imaginação, conforme eu e Elyana Barbosa mostramos no livro que escrevemos juntas e que tem este título.

Segundo Léon Brunschvicg, seu mestre, Bachelard costumava dizer que era muito mais professor do que filósofo. Contrário a dogmatismos, a certezas absolutas e definitivas, Bachelard propõe uma pedagogia que se fundamenta na polêmica e no diálogo semelhante ao que existe em sala de aula entre mestre e aluno, ambos usufruindo da troca de ideias e se enriquecendo mutuamente. Assim, nos dias de hoje considero importante que se leia Bachelard, principalmente em nosso país. Vivemos atualmente a pandemia de coronavirus que assola o mundo inteiro e temos que nos orientar pela ciência e não assumir uma atitude negacionista, não aceitando o que médicos e especialistas dizem sobre a contaminação pelo vírus, como fazem certos políticos e o próprio presidente da república. Conforme mostra Bachelard, a ciência 
estabelece seus conhecimentos através do racionalismo aplicado e da polêmica que ocorre na "cidade científica", o que faz com que esta alcance um saber consistente e que deve, portanto, ser acatado.

É preciso ressaltar também a importância para a arte e para a cultura da pedagogia da imaginação que emerge da leitura da vertente poética bachelardiana. Bachelard mostra que um dos objetivos principais da educação deve ser estimular a criação e afastar as imagens esclerosadas que nos são impostas por um ensino pernicioso.

Bachelard propõe, pois, uma pedagogia que estimula a criação, não só da razão, como da imaginação. Mostra que o ato de conhecer e o de imaginar implicam em se aventurar num mundo novo, fazendo do abrupto e do excepcional uma nova regra, construindo novas ideias e novas imagens, renegando os ensinamentos da tradição. O convívio em sociedade nos leva a sufocar o dom criador que todos nós possuímos, através de regras que nos são impostas. Com Bachelard aprendemos a nos insurgir contra a ociosidade do ensino tradicional, cuja proposta é a de transmitir ideias prontas e acabadas.

O Brasil recebeu grande influência dos países desenvolvidos, como os Estados Unidos, o que levou nosso país a absorver os valores pós-modernos de ordem pragmática que regem as sociedades capitalistas. Com Bachelard o estudante brasileiro vai poder aprender o verdadeiro ideal de cultura e educação, ideal este que nos adverte contra a ociosidade, traço marcante das sociedades de consumação passiva.

É, pois, muito importante estudar Bachelard para aprendermos o verdadeiro sentido de educação. Educação, para nosso filósofo, é, pois, formação, mas é preciso ressaltar que formação é desconstrução e reforma do sujeito que, retificando suas ideias faz de seu dinamismo e de sua inconstância a exigência pedagógica mais fundamental. Assim, o processo de formação do sujeito não é de forma alguma passivo, mas, ao contrário, é resultado de um esforço contínuo e permanente, pois a atividade mais essencial do sujeito é a de se enganar, o que nos leva a concluir que nos educamos através da perda de nossas ilusões primeiras, através da retificação de nossos erros. Daí a importância de estudarmos e de divulgarmos nos meios acadêmicos a obra de Bachelard.

A presença da criança nos escritos bachelardianos reforça o que acabamos de dizer e corrobora a importância de aprendermos com Bachelard a necessidade de mantermos na fase adulta 
o espírito de criança. A criança consegue, por um lado, habitar um mundo imaginário e onírico, tendo como tesouro a proliferação de imagens; por outro lado, sua racionalidade é aberta e não dogmática, já que a razão é ainda nascente na infância. Lendo Bachelard, vamos aprender como manter na idade adulta o equilíbrio entre razão e imaginação dinâmicas que é próprio da criança, pois, para Bachelard, razão e imaginação só têm sentido enquanto atividades de conquista.

Para encerrar a entrevista, que acredito, já se alongou além do tempo que tinha, gostaria de contar uma história interessante que se passou comigo. Em 2001 o Prof. Jean-Jacques Wunenburger que, na época, ainda não conhecia, me pediu que eu fizesse um dossiê sobre a recepção de Bachelard no Brasil. Nesta data ainda não era comum pesquisas pela internet e, embora eu conhecesse alguns pesquisadores brasileiros da obra bachelardiana, havia um grande número que eram desconhecidos por mim e, aos quais pude conhecer na ocasião e me tornar amiga, além de passar a compartilhar ideias numa troca dinâmica e produtiva. Auxiliada pelos alunos que sempre me ajudaram muito, comecei a encontrar estudiosos de Bachelard em universidades do Rio de Janeiro e de outros estados do Brasil.

Quando o dossiê ficou pronto, pensei que seria interessante procurar algum pesquisador brasileiro que tivesse sido aluno de Bachelard na França. Meu intuito era começar o dossiê com o testemunho deste pesquisador. Soube de um poeta em São Paulo, mas logo em seguida me disseram que ele já tinha falecido. Desanimada, depois de uma procura infindável e sem sucesso, me dirigi a UERJ para dar minha aula. Tendo que aguardar o meu horário para entrar em sala, resolvi, enquanto esperava, me sentar num banco que ficava diante da lanchonete. O Prof. Gerd Bornheim, grande mestre e pesquisador brasileiro de renome, sentou-se a meu lado, pois também aguardava seu horário de aula. Contei-lhe, então, sobre minha preocupação no momento, pois desejava encontrar um brasileiro que tivesse sido aluno de Bachelard, o que estava sendo difícil. Disse-me ele, então, com toda calma: Mas você, Marly, está sentada ao lado dele! Não podem imaginar a grande alegria que senti. Pedi-Ihe que escrevesse um testemunho à respeito do filósofo, o que aceitou prontamente. E, no dia seguinte, eu estava com o testemunho em minhas mãos.

O Dossiê Bachelard au Brésil ficou muito bom, continha vários artigos de pesquisadores brasileiros que abordavam o pensamento de Gaston Bachelard a partir de facetas as mais diversas. Começava com uma introdução do Prof. Jean-Jacques Wunenburger e outra minha, 
seguidas do testemunho do Prof. Gerd Bornheim que dizia: "Eu me lembro com uma ternura especial dos cursos excepcionais de Bachelard na Sorbonne [...]; prosseguia: - "a recapitulação é senão a morte das ideias. Tratava-se, ao contrário, de ideias vivas que ele quase que improvisava, tudo isso pleno de pensamentos de uma vida inteira" (BORNHEIM, 2001, p.14).

No final do texto Gerd relatava um fato muito interessante que se passara no início de uma das aulas que assistira quando era aluno. Conta que Bachelard morava na Place Maubert, bem próxima a Sorbonne, o que permitia que viesse caminhando. Certo dia, entrara na aula, com a fisionomia meio carrancuda, meio zangado. Os alunos estranharam, pois o filósofo estava sempre sorrindo. Ele, então, explicou que alguns turistas haviam olhado para ele com espanto, começando a rir com ar de deboche, olhando para ele como se fosse uma peça de museu. Escreve, então, Gerd Bornheim: "Bachelard usava calças de época, um colete e, como exige o rigor, uma sobrecasaca, nos pés usava sapatos finos com uma polaina por cima. Coroando tudo isto, vinha a cabeleira branca comprida e cacheada e uma barba também branca que lhe envolvia o rosto" (BORNHEIM, 2001, p.15). Então, Gerd Bornheim, o mestre saudoso que morreu há poucos anos, termina seu testemunho dizendo:

\begin{abstract}
A bela figura de nosso pensador representava seu papel com a perfeição de um ator. [...] Na memória daqueles que o assistiram, Bachelard continua a ser, sem dúvida, uma presença única pelo estilo do seu discurso pela energia de seu pensamento e por ser um remarcável criador de ideias, isso tudo a maneira de um mestre dos mestres (BORNHEIM, 2001, p.15).
\end{abstract}

Agradeço imensamente o convite e a todos que me assistiram. Era isto que eu tinha para falar. Obrigada!

\title{
Questões
}

Gabriel Kafure: Marly, temos algumas questões.

Farei a primeira que é da Anne Marie Bruno. "Como na caverna de Platão?" Ela está, com certeza, se referindo à imagem.

Gabriel Kafure: Aproveito para completar a pergunta dela com uma pergunta minha. "Qual a diferença entre a imagem simulacro e a imagem material de Bachelard?" 
Marly Bulcão: Platão é também um dos filósofos favoritos para mim. Fiz alguns trabalhos sobre seu pensamento. Mas Platão e Bachelard viveram em contextos muito diferentes, então suas problemáticas não são as mesmas. Mas, na filosofia, do meu ponto de vista, desde que você ressalte as diferenças e mostre as semelhanças, desenvolvendo uma argumentação coerente, torna-se possível fazer um trabalho comparativo. Vejo, entretanto, no caso de Platão e Bachelard, profundas diferenças, pois em Platão a ideia é considerada como a verdadeira realidade. Bachelard está preocupado em mostrar a autonomia da imagem que pode mesmo superar a realidade.

Gabriel Kafure: Marly, tenho aqui uma pergunta da Profa Vera Portocarrero. Ela pergunta: "Quais as categorias bachelardianas que você considera mais relevantes no seu estudo sobre o cinema?"

Marly Bulcão: A Vera está sempre me provocando com perguntas inteligentes, o que é muito bom. Considero principalmente, na abordagem sobre Bachelard e o cinema dois aspectos, o da imagem material e o da noção de instante. Para Bachelard, a imagem é, como disse na entrevista, um acontecimento objetivo que integra uma imagética. A imaginação material resulta de um embate com o mundo, pois a imaginação precisa do trabalho concreto do mundo. Da mesma forma a imagem do cinema nos causa um impacto e é neste sentido eminentemente material. O outro aspecto que considero é a noção de tempo como instante. Para Bachelard, o tempo verdadeiro é o instante, o aqui e o agora instantâneos. E o cinema é, na verdade, uma construção de instantes.

Gabriel Kafure: Tenho também uma pergunta do Marcelo de Carvalho, que é, aliás, uma afirmação para você comentar. "Nos conte sobre a aventura de Bachelard nos cursos sobre Lautréamont na Paris ocupada pelos nazistas".

Marly Bulcão: Em seu Lautréamont, Bachelard mostra uma imaginação que é essencialmente material e agressiva. É uma imaginação que emerge da interioridade, da primitividade do ser humano. O poema do Conde de Lautréamont intitulado Os Cantos de Maldoror, fala, através de uma linguagem poética, de imagens agressivas. Refere-se ao caranguejo e ao piolho como símbolos de violência e agressão. Creio que o Marcelo quer que eu fale de um relato que aparece no livro Un été avec Bachelard de autoria do poeta Jean Lescure, amigo de Bachelard e no qual o autor conta que costumavam ler em conjunto o livro 
Lautréamont durante os momentos em que Paris estava sendo ocupada pelos nazistas e a violência predomina na cidade. Mas o importante é dizer que Bachelard vai procurar mostrar como a agressividade pode se manifestar sob a forma de uma linguagem poética.

Marly Bulcão: Agradeço mais uma vez o convite para a entrevista e as questões levantadas que me permitiram mostrar mais um pouco a importância do estudo de Gaston Bachelard.

\section{Referências}

BACHELARD, G. Fragments d'une poétique du feu, Paris: PUF, 1988.

BACHELARD, G. La poétique de l'espace, Paris: PUF, 1998.

BACHELARD, G. La psychanalyse du feu, Paris: Gallimard, 2002.

BORNHEIM, G. Souvenir et présence de Bachelard. Cahiers Gaston Bachelard (Bachelard au Brésil coordené par Marly Bulcão), Dijon, Université de Bourgogne, n.4, p.14-15, 2001.

LECOURT, D. Bachelard - Le jour et la nuit, Paris: Bernard Grasset, 1974. 